\title{
Advancing Experimental Research and Instrumentation in the Laboratory in Understanding the Moon
}

Caitlin Ahrens ${ }^{1}$ (332 N Arkansas Ave., Fayetteville, AR 72701, ca006@uark.edu)

Matt Siegler ${ }^{2}$; Indhu Varatharajan ${ }^{3}$; Kerri Donaldson Hanna ${ }^{4}$; Katherine Shirley ${ }^{5}$; Tristram Warren ${ }^{5}$

${ }^{1}$ Arkansas Center for Space and Planetary Sciences; ${ }^{2}$ Planetary Science Institute; ${ }^{3}$ DLR Institute of Planetary Research; ${ }^{4}$ University of Central Florida; ${ }^{5}$ University of Oxford;

Endorsers: Nandita Kumari (Stony Brook University); Timothy Glotch (Stony Brook University); Jamie Cook (NASA GSFC)

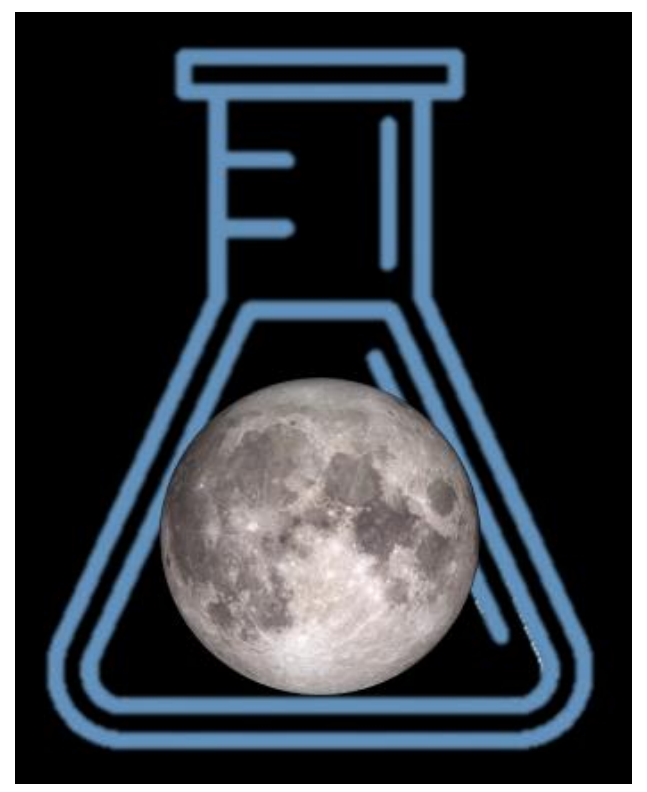




\section{Abstract}

From the Apollo-era to present day, we know the Moon consists of a variety of minerals, rocks (and agglutinates), glasses, and volatile molecules. Laboratory measurements of physical and chemical properties of such materials generate key support for a variety of experimental endeavors. These measurements provide objectives of ground-based, orbital, and lander observations; instrument and mission design; and interpretation of retrieved data products. In some situations, models take the lead in characterizing these materials, especially where observational or direct measurements are lacking. Laboratories for the purpose of spectroscopy, geochemistry, impact studies, etc. continue to operate for the purpose of studying these materials so that we may understand our natural satellite.

We recommend increased support for such laboratory research of the physical (rheological, thermal) and chemical (mineralogical, isotopic) properties of lunar material, especially being relevant to future space missions to the Moon and extend our knowledge of these lunar materials in experimental settings.

\section{Science Rationale and Objectives}

We summarize in this white paper a collective effort of the lunar science community in outlining the scientific need for experimental research, including advancement of instrumentation, and its direction for future NASA mission studies, and the coming 2023 Decadal Survey to the National Research Council. This white paper addresses the components and motivations to the experimental explorations of the lunar surface. The following science objectives for lunar experimental research are:

- Regolith studies and simulant synthesis (see white paper by Denevi et al. 2020)

- Thermophysical properties of lunar materials (e.g., returned samples, meteorites, and analogs)

- Spectroscopy of lunar returned-samples, meteorites, and analogs

- Isotopic constraints

- Grain physics (e.g., stickiness, tensile strength)

- Magnetic effects (see Ciscowski et al. 1973)

- Sample return studies

- Irradiation and space weathering of materials (see white paper by Thompson et al. 2020)

- Advancement of experimental instruments and techniques

The discussion is divided into three main sections, addressing fundamental questions as they pertain to the advancement of lunar laboratories:

-What lunar discoveries require laboratory investigation?

-What are the key challenges? 
-Addressing fundamental issues as they pertain to the advancement of lunar laboratories.

A comprehensive table on specific science investigations benefiting from laboratory research is in Table 1.

Table 1: Mission observations, modeling, and laboratory approaches to key lunar questions.

\begin{tabular}{|c|c|c|c|}
\hline Science Questions & $\begin{array}{l}\text { Ground-based, Fly- } \\
\text { by, Orbiter, } \\
\text { Astronautic } \\
\text { Observation }\end{array}$ & Modeling Approach & $\begin{array}{l}\text { Laboratory } \\
\text { Measurement }\end{array}$ \\
\hline $\begin{array}{l}\text { What is the composition } \\
\text { of the surface material? } \\
\text { What is the mineralogy of } \\
\text { the lunar surface? }\end{array}$ & $\begin{array}{l}\text { UV/VIS/IR/X- } \\
\text { ray?Gamma ray/Neutron } \\
\text { spectroscopy; } \\
\text { Radiometer; } \\
\text { Radar; } \\
\text { Density; } \\
\text { Sample return, collected } \\
\text { meteorites }\end{array}$ & $\begin{array}{l}\text { Regolith layering; } \\
\text { Buoyancy of materials; } \\
\text { Volatile interactions; } \\
\text { Spectral radiative transfer } \\
\text { modeling; } \\
\text { Spectral linear and non- } \\
\text { linear mixture modeling }\end{array}$ & $\begin{array}{l}\text { Thermophysical (density, } \\
\text { heat capacity, latent heat); } \\
\text { Thermodynamic } \\
\text { (pressure-volume, } \\
\text { equations of state); } \\
\text { Rheological (strain rates, } \\
\text { brittleness-ductility, } \\
\text { viscosity); } \\
\text { Dielectric parameters; } \\
\text { UV/VIS/IR Spectroscopy } \\
\text { (spectral } \\
\text { parameters/features) }\end{array}$ \\
\hline $\begin{array}{l}\text { What are the regolith } \\
\text { properties? }\end{array}$ & $\begin{array}{l}\text { UV/VIS/IR spectroscopy; } \\
\text { Density; } \\
\text { Radiometer; } \\
\text { Radar; } \\
\text { Sample return }\end{array}$ & $\begin{array}{l}\text { Thermal modeling; } \\
\text { Thermal evolution; } \\
\text { Buoyancy; } \\
\text { Mineral endmember } \\
\text { evolution/weathering }\end{array}$ & $\begin{array}{l}\text { Thermophysical (density, } \\
\text { heat capacity, } \\
\text { conductivity, latent heat); } \\
\text { dielectric parameters; } \\
\text { acoustic velocities; } \\
\text { Particle size } \\
\text { distribution/morphologies; } \\
\text { Optical maturity; } \\
\text { UV/VIS/IR spectroscopy }\end{array}$ \\
\hline $\begin{array}{l}\text { What are the radiative } \\
\text { processes and surface } \\
\text { evolution? }\end{array}$ & $\begin{array}{l}\text { Radiometer; } \\
\text { Heat flux; } \\
\text { UV/VIS/IR/X- } \\
\text { ray/Gamma ray/Neutron } \\
\text { spectroscopy }\end{array}$ & $\begin{array}{l}\text { Radiative evolution; } \\
\text { Thermal evolution }\end{array}$ & $\begin{array}{l}\text { Sublimation; } \\
\text { Phase stability; } \\
\text { Ion/photon radiation; } \\
\text { Heat capacity; } \\
\text { Conductivity; Scattering } \\
\text { properties }\end{array}$ \\
\hline $\begin{array}{l}\text { What is the geochemistry } \\
\text { of the lunar surface? }\end{array}$ & $\begin{array}{l}\text { UV/VIS/IR/X- } \\
\text { ray/Gamma ray/Neutron } \\
\text { spectroscopy; } \\
\text { Lyman-Alpha mapping; } \\
\text { Cosmic Rays detector; } \\
\text { Radiometer; } \\
\text { Sample return }\end{array}$ & $\begin{array}{l}\text { Temporal evolution of } \\
\text { isotopic chemistry; } \\
\text { Mineral endmember } \\
\text { evolution/weathering; } \\
\text { Spectral radiative transfer } \\
\text { modeling; } \\
\text { Spectral linear and non- } \\
\text { linear mixture modeling }\end{array}$ & $\begin{array}{l}\text { Ionization; } \\
\text { Mass spectroscopy; } \\
\text { Laser ablation; } \\
\text { UV/VIS/IR spectroscopy }\end{array}$ \\
\hline $\begin{array}{l}\text { What are the magnetic } \\
\text { properties of the regolith? }\end{array}$ & $\begin{array}{l}\text { Magnetometer; } \\
\text { Density; } \\
\text { UV/VIS/IR } \\
\text { Sample return }\end{array}$ & $\begin{array}{l}\text { Vapor-phase deposition; } \\
\text { Metamorphism over } \\
\text { longer timescales }\end{array}$ & $\begin{array}{l}\text { Dielectric parameters; } \\
\text { Heating/thermal } \\
\text { properties }\end{array}$ \\
\hline
\end{tabular}




\section{What Planetary Discoveries Require Laboratory Investigation?}

Here we include a few examples of key lunar surface features or observations of the lunar surface that specifically need laboratory investigations to advance our understanding of the outstanding science questions for these features.

\section{- Permanently shadowed regions}

Permanently shadowed craters are a recent discovery at the lunar poles and are still an enigma as to their behavior and evolution. Recent observations have shown certain craters appear to have asymmetries in potential ice deposits as well as variation of temperatures based on measurements from Lunar Reconnaissance Orbiter's Lunar Orbiter Laser Altimeter (LRO-LOLA), Diviner Lunar Radiometer Experiment (Diviner), Lunar Crater Observation and Sensing Satellite (LCROSS), and Moon Mineralogy Mapper (M ${ }^{3}$ ) (e.g., Schultz et al. 2010; Siegler et al. 2015; Li et al. 2018).

Hayne et al. (2015) found that many PSR's near the lunar south pole have maximum surface temperatures $<100 \mathrm{~K}$, consistent with the presence of stable water ice found using LRO's Lyman Alpha Mapping Project (LAMP; Gladstone et al. 2010), though the LRO Neutron Detector Experiment LEND datasets are inconsistent with this finding (Mitrofanov et al. 2010). Surface temperatures in these shadowed regions are largely controlled by reflected sunlight and irradiated infrared light from adjacent topography (Ingersoll et al. 1992; Salvail and Fanale 1994). These areas act as cold traps, capable of accumulating water and other volatile compounds over time (Li et al. 2018).

These studies are important for better understanding the water-volatile cycle and transport on the Moon, and human and robotic explorations (e.g., sampling by drills, trafficability for rovers). Possible laboratory investigations toward understanding permanently shadowed regions and relative volatiles would include:

- $\quad$ Thermal studies, including conductivity

- $\quad$ Sublimation pressures at low temperatures

- $\quad$ Neutron and mass spectroscopy

- $\quad$ Rheological studies, including latent heat and dielectric properties

- $\quad \mathrm{UV} / \mathrm{VIS} / \mathrm{IR}$ spectral studies of water ice and other volatiles mixed with regolith/simulants

\section{- Lunar magma ocean}

The hypothesis that the primordial Moon was partially molten came from the analyses of Apollo samples returned from the lunar highlands (e.g., Wood et al. 1970; Dowty et al. 1974). From this melt, anorthite plagioclase was buoyantly segregated, forming an anorthositic crust (Smith et al., 1970; Wood et al., 1970). The age of these highlands (Nyquist and Shih, 1992) and experimental 
evidence that plagioclase is not present on the liquidus of mare basalts (Green et al., 1971) are all strong supporting evidence for an early, major differentiation event. However, recent lab measurements suggest more Mg-type rocks (Elardo et al. 2011). Crystallization of the lunar magma ocean (LMO) is thought to create a series of differing chemical compositions and mineralogical assemblages (Warren 1985; Shearer et al. 2006). The crystallization sequence and composition of these layers in the lunar interior have led to studies of modeled magma ocean crystallization for a variety of ocean depths and compositions (Li et al. 2017).

Possible laboratory investigations toward understanding the lunar magma ocean would include:

- $\quad$ Isochron dating of lunar meteorites, and KREEP basalts (Elkins-Tanton et al. 2011)

- $\quad$ Laser ablation resonance ionization mass spectroscopy (Anderson et al. 2015)

- $\quad$ High pressure, high temperature crystallization experiments (Lin et al. 2017)

- UV/VIS/IR spectral studies of lunar anorthosites and terrestrial analogs

\section{- Impact cratering}

Impact craters on the Moon are so varied in size, structure, and mineralogy, that a number of experiments can investigate. This includes how crater ejecta can form, how crater rays are formed, the porosity of the material and the impactor (Avdellidou et al. 2016; Michikami et al. 2007), how secondary crater structures are created, cold trapping processes (like those with permanently shadowed regions), and oblique impacting processes (Gault and Wedekind 1978).

Possible laboratory investigations toward impact cratering on the Moon would include:

- $\quad$ Oblique (and differing angles) of the impactor (Schultz et al. 2011)

- $\quad$ Compressional and shear stresses from the impactor (Melosh et al. 1992)

- $\quad$ Thermal relaxations of the regolith and resulting ejecta

- $\quad$ Resulting impact structure over mineralogically stratified units

- Impact cratering over permanently shadowed regions

\section{- Lunar Swirls}

Lunar swirls are enigmatic high albedo and complex sinuous shape features distributed across the lunar surface. The Moon has no intrinsic magnetic field, but these swirls are associated with locally high magnetic field strength. These mini-magnetospheres around the swirls deflect the impacting solar wind ions due to the shielding magnetic field. This reduces the effects of space weathering due to ion implantation and sputtering; however, the magnetic field cover cannot screen out micrometeorites. The origin and nature of swirls still remain a mystery (Hood and Williams 1989; Garrick-Bethell et al. 2011; Blewett et al. 2011). Understanding the formation and nature of lunar swirls will help us to bridge the gap between lunar geology, magnetism, and space weathering. This makes lunar swirls a natural laboratory that would help us to investigate the importance of micrometeorite bombardment vs. solar wind sputtering/implantation processes in the optical weathering of lunar regolith. 
Possible laboratory investigations toward better understanding the origin of lunar swirls would include:

- $\quad$ Investigating the source of magnetism with depth

- Geochemistry and mineralogy of the surface materials in and around the swirls

- $\quad$ Crustal magnetism and its influence on solar wind ion sputtering

\section{- $\quad$ The Lunar Interior}

Since the seismometers were placed on the Moon by the Apollo program (Latham et al. 1969), our knowledge regarding the interior of the Moon has expanded. Now with the advancement of seismic technology and testing extra-planetary seismometers remotely (InSight on Mars; Lognonne, et al. 2019), the advocacy for more lunar seismometers is warranted (and other instrumentation, such as penetrator technology—see white papers by Paige et al. 2020 and Nunn et al. 2020).

Possible laboratory investigations toward understanding the lunar interior would include:

- $\quad$ Compressional and shear stresses

- $\quad$ Acoustic velocities with differing materials (e.g., grain sizes, porosity, thicknesses)

- $\quad$ Development and improvement on low-temperature seismometers and seismic noise floor technology

Several lunar missions are currently active or in the works for future exploration. However, certain instruments onboard those missions must be advocated due to their crucial importance to experimental research of the lunar surface. These include compositional mapping, solar irradiation and space weathering, radar, etc.

Advancements in modeling capabilities can certainly further assist in long-term processes over numerous lunar cycles and seasons, far beyond the limitations of laboratory experiments. However, experimental research can, in turn, define certain parameters and constraints for models.

Many of these questions are not exclusive to any one single lunar process in the lunar community and answering them will require an interdisciplinary and collaborative approach. For example, interpreting the discovery of water ice at the lunar poles is a problem of impact cratering, thermophysics, and space weathering.

\section{What are the Key Challenges?}

Laboratory research delves into the mysteries of (but are not limited to) surface composition and processes (including space weathering), and the lunar interior. Our experimental investigation of the Moon includes measurements of materials (e.g., isotopes, geochemistry, mineralogy, etc.) 
that requires controlled sampling, reproducibility and verification of results, and interpretation of results. A few key challenges of experimental research include:

(i) Careful laboratory preparation to handle returned samples (see white papers by Jolliff et al. 2020; Lawrence et al. 2020; Moriarty et al. 2020), and careful recreation of lunar regolith simulants for more widespread distribution.

(ii) Instrumental construction, calibration, and analysis. This could also include instrumentation being tested in the laboratory for potential future lunar missions, such as orbiters and human exploration.

(iii)Time and funding from sample preparation to instrument calibration, and often expenses to run certain specialized equipment or analysis software (which may require time for training prior to experimentation).

(iv) Simulating the lunar daytime and nighttime vacuum environment under controlled laboratory conditions. This will add in testing the repeatability of the results across laboratories and also apply the results directly to the orbit- and surface-based instruments.

\section{Recommendations to the Lunar and Planetary Communities}

Based on the above details, we recommend that the Lunar Exploration Analysis Group (LEAG), Committee on Astrobiology and Planetary Sciences (CAPS), and Decadal Survey review panel support the following points (in no particular rank):

(a) Improvement of coordination between laboratories working on lunar experiments and simulations for the improvement of networking and understanding of lunar material science.

(b) Establishment of a database for sharing funded laboratory results (e.g. Planetary Data System).

(c) Support the role of experimental research as a key component of lunar exploration. This also includes funding for support staff to run key analytical and experimental equipment.

(d) Increased inclusion and representation from the laboratory research community within respective professional societies and assessment groups.

(e) Increased provisional funding inside mission proposals to support laboratory work dedicated to support specific mission instrumentation testing and planning the development of science requirements. 


\section{References}

Anderson, F., et al. (2015) Rapid Comm. Mass Spec. 29 (16), 1457-1464.

Avdellidou, C., et al. (2016) MNRAS 456 (3), 2957-2965.

Blewett, D., et al. (2011) JGR: Planets, 116 (E2).

Ciscowski, S. et al. (1973) Proc. of the Lunar Science Conference, vol. 4, Abstract 3003.

Denevi, B., et al. (2020) Key questions in regolith development on planetary bodies: depth, distribution, processes. NAS white paper submitted to the Planetary Science decadal survey committee.

Dowty, E., et al. (1974) EPSL, 24, 15-25.

Elardo, S., et al. (2011) Geochimica et Cosmochimica Acta, 75 (11), 3024-3045.

Elkins-Tanton, L., et al. (2011) EPSL, 304, 326-336.

Garrick-Bethell, I., Head, J., Pieters, C. (2011) Icarus, 212 (2), 480-492.

Gault, D., and Wedekind, J. (1978) $9^{\text {th }}$ LPSC, Abstract 3843.

Gladstone, G.R., et al. (2010) Space Sci. Rev.150(1-4), 161-181

Green, D., et al. (1971) Proc. Lunar Sci. Conf. 2, 601-615.

Hayne, P., et al. (2015) Icarus, 255, 58-69

Hood, L. and Williams, C. (1989) LPSC Abstract 99.

Ingersoll, A., et al. (1992) Icarus, 100, 40-47.

Jolliff, B., et al. (2020) Sample return from the South Pole - Aitken Basin. NAS white paper submitted to the Planetary Science decadal survey committee.

Latham, G., et al. (1969) Science, 165 (3890), 241-250.

Lawrence, S., et al. (2020) Samples from young lunar terrains. NAS white paper submitted to the Planetary Science decadal survey committee.

Li, S., et al., (2018) PNAS, 115 (36), 8907-8912.

Li, Y. et al. (2017) Nature Geoscience, 10, 14-18.

Lognonne, P., et al. (2019) Space Sci. Rev., 215 (1): 12.

Melosh, H., Ryan, E., Asphaug, E. (1992) JGR: Planets, 97 (E9), 14735-14759.

Michikami, T. et al. (2017) PSS, 55 (1-2), 70-88.

Mitrofanov, I., et al. (2010) Science, 330 (6003) 483-486.

Moriarty, D., et al. (2020) Sample return to multiple target locations. NAS white paper submitted to the Planetary Science decadal survey committee.

Nunn, C., et al. (2020) MoonShake: a Lunar Seismic Network Delivered by Penetrators. NAS white paper submitted to the Planetary Science decadal survey committee.

Nyquist, L., and Shih, C. (1992) Geochem. Cosmochim. Acta 56, 2213-2234.

Paige, D., et al. (2020) Small penetrator for Lunar Polar Science and Exploration. NAS white paper submitted to the Planetary Science decadal survey committee.

Salvail, J., Fanale, F., (1994) Icarus, 111, 441-455.

Shearer, C., et al. (2006) New Views Moon Rev. Mineral. Geochem. 60, 365-518.

Shultz, P., et al. (2007) Icarus, 191 (2), 84-122.

Shultz, P., et al. (2010) Science, 330 (6003), 468-472.

Siegler, M., et al. (2015) Icarus, 255, 78-87.

Smith, J.V., et al. (1970) Proc. Apollo 11 Lunar Sci. Conf. 1, 897-925.

Thompson, M., et al. (2020) Space weathering across the Solar System: lessons from the Moon and outstanding questions. NAS white paper submitted to the Planetary Science decadal survey committee.

Warren, P. (1985) Annu. Rev. Earth Planet. Sci. 13, 201-240.

Wood, J., et al. (1970) Proc. Apollo 11 Lunar Sci. Conf. 965-988. 